\title{
ANALYSIS OF SPATIAL PATTERN AND INFLUENCING FACTORS OF E-COMMERCE
}

\author{
Yaxuan Zhang ${ }^{\mathrm{a}}$, Jiangping Chen ${ }^{\mathrm{a}}$, Shuming Zhang ${ }^{\mathrm{a}}$ \\ ${ }^{a}$ School of Remote Sensing and Information Engineering, Wuhan University, Wuhan, China
}

Commission IV, WG IV/3

KEY WORDS: E-commerce, spatial pattern, spatial autocorrelation, influencing factor, geographical weighted regression

\begin{abstract}
:
This paper aims to study the relationship between e-commerce development and geographical characteristics using data of e-commerce, economy, Internet, express delivery and population from 2011 to 2015 . Moran's I model and GWR model are applied to analyze the spatial pattern of E-commerce and its influencing factors. There is a growth trend of e-commerce from west to east, and it is obvious to see that e-commerce development has a space-time clustering, especially around the Yangtze River delta. The comprehensive factors caculated through PCA are described as fundamental social productivity, resident living standard and population sex structure. The first two factors have positive correlation with e-commerce, and the intensity of effect increases yearly. However, the influence of population sex structure on the E-commerce development is not significant. Our results suggest that the clustering of e-commerce has a downward trend and the impact of driving factors on e-commerce is observably distinct from year to year in space.
\end{abstract}

\section{INTRODUCTION}

In recent years, e-commerce is developing by leaps and bounds. Its profound influence not only penetrates in all trades, but also becomes prevalent among many regions (Hao et al., 2016). Meanwhile, its spatial distribution pattern is changing every year dramatically and there are many other factors promoting the development of e-commerce (Tang, 2015). According to the latest data from the China Electronic Commerce Research Center, we know that the amount of online shopping users in China is up to 360 million and the turnover has already been more than $\$ 350,000,000,000$ (Zhu et al., 2016). In other words, it accounts for $10 \%$ of retail sales (Xu, 2013).

Sendy Farag etc. reported investigation of the spatial distribution of Internet users and online buyers in the Netherlands for the time period 1996-2001 and the impact of residential environment and shop accessibility on e-shopping (Farag et al., 2006). Yuko Aoyama analyzed how sociospatial factors, such as urban form, consumer preference, and cultural attributes shape the patterns of E-commerce in Japan (Aoyama, 2003). At yet, few researchers have examined Chinese e-shopping from a spatial perspective and they seldom concern the impact of spatial variables on eshopping. Consequently, we try to include space-time accessibility measures in our analysis.

In this paper, we apply some research methods of GIS, studying e-commerce not only in traditional time dimension, but also in space dimension. Through combining datasets of express delivery, economies, Internet and population, we further observe the interaction between e-commerce and above data. In this way, we are able to build a more objective model of e-commerce. The study of this paper provides practical guidance for conducting e-shopping and provides innovative methods for similar research.

\section{DATA AND METHODOLOGY}

\subsection{Data}

The data in the facets about E-commerce, express delivery, economy, Internet and population from 2011 to 2015, classified by province (excluding Taiwan, Hong Kong and Macao), e.g. "the turnover of E-commerce", "the provincial GDP", "the level of consumption", "the number of Internet users", "Internet popularity rate", "the turnover of express", "the number of express goods", " the number of express outlets", "the provincial population", "the provincial sex ratio", "the structure of education in population" and "the structure of age in population".

\subsection{Methodology}

In this paper, we apply the global spatial autocorrelation calculated by using Morans model to study the overall spatial pattern throughout mainland, which can evaluate whether data clusters in space. On this basis, we use local Morans model to measure the spatial correlation between each province and the surrounding areas. Next we use principal component analysis to get the comprehensive factors. Then we set these factors as the variables of the GWR model and analyze the intensity of each factors influence in different regions.Furthermore, we can analyze the tendency of the e-commerce development and make scientific prediction to the objective development spatial pattern.

2.2.1 Spatial Autocorrelation Analysis Moran 's $I$ is a statistical index which is used to make spatial autocorrelation analysis, proposed by Moran in 1948 (Wang and Xu, 2011). The main function of this index is to reveal the overall spatial distribution agglomeration of e-commerce and to explain whether the spatial autocorrelation exists or not. The formula is defined as follows:

$$
I=\frac{n * \sum_{i}^{n} \sum_{j}^{n} w_{i j} *\left(x_{i}-\bar{x}\right)\left(x_{j}-\bar{x}\right)}{\left(\sum_{i}^{n} \sum_{j}^{n} w_{i j}\right) * \sum_{i}^{n}\left(x_{i}-\bar{x}\right)^{2}}
$$

The formula of its expected value is:

$$
E(I)=-1 /(n+1)
$$


The range of Moran 's $I$ is $[-1,1]$, the greater the absolute value, the higher the degree of correlation and the spatial autocorrelation of the provincial e-commerce development. When Moran 's $I<E(I)$, there is a negative correlation between provinces. When Moran 's $I>E(I)$, there is a positive correlation between provinces. However we also need to use the standardized $Z$ value to test whether the difference has statistical significance. According to the normal distribution test value, if the absolute value of $Z$ value is greater than $1.65(1.96)$, when the normal distribution function at $0.05(0.01)$ level, it shows that the attribution between regions has significant positive spatial autocorrelation; similarly, if the absolute value of $Z$ value is less than 1.65(1.96), it indicates that the attribution between regions has a significant negative spatial autocorrelation.

However, global spatial autocorrelation can only reflect wether there are spatial clustering effects of the e-commerce development, and it isn't able to describe which provinces have high value aggregation or low value aggregation (Xiao, 2014). Local spatial autocorrelation can find e-commerce geographically aggregate in which specific provinces and in which specific pattern (high-high or low-low). The local Moran 's I of province $k$ is calculated as:

$$
\text { Moran's } I_{k}=\frac{\left(x_{k}-\bar{x}\right)}{\sum_{k=1}^{m}\left(x_{k}-\bar{x}\right)^{2}} * \sum_{h \neq k}^{m} W_{k h}^{\prime}\left(x_{h}-\bar{x}\right)
$$

The expected value of local Moran's $I\left(E_{k}\left(I_{k}\right)\right)$ is:

$$
E_{k}\left(I_{k}\right)=-\sum_{h=1}^{m} W_{k h} /(m+1)
$$

When Moran's $I_{k}>E_{k}\left(I_{k}\right)$, it can be deduced that there exists a similar e-commerce agglomeration phenomenon in the neighbor areas of province $\mathrm{k}$, namely the existence of a positive local spatial autocorrelation. And when Moran's $I_{k}<E_{k}\left(I_{k}\right)$, it can be deduced that the e-commerce in province $\mathrm{k}$ and its neighbor areas differ greatly, that is, there is a tendency of negative local spatial autocorrelation.

2.2.2 Principal Component Analysis Principal component analysis (PCA) is mainly based on the feature analysis of covariance matrix to achieve the purpose of maintaining the maximum contribution of data sets to variance and reducing the dimension of data (Wang et al., 2014). Namely, in the case of minimal loss of data information, we come up with some component by reducing the dimension of the original indicators into one or several comprehensive factors. The amount of the selection of the principal component is not only to meet the purpose of reducing the dimension of data, but to integrate as much information as possible. Usually, we use a criterion that the cumulative variance contribution rate is not lower than a threshold (e.g. 85\%) to determine the number of principal components (Wang et al., 2014).

2.2.3 Geographical Weighted Regression Through an extension of the traditional regression model, geographically weighted regression(GWR) can make the parameters be locally estimated. The formula of GWR is as follows:

$$
y_{i}=\beta_{0}\left(u_{i}, v_{i}\right)+\sum_{k} \beta_{k}\left(u_{i}, v_{i}\right) x_{i k}+\epsilon_{i}
$$

According to formula(5), $\left(u_{i}, v_{i}\right)$ represents the spatial coordinates of $\mathrm{i}$-th sample points; $\beta_{k}\left(u_{i}, v_{i}\right)$ represents the function value; $\varepsilon$ is random error. In this formula, the kernel function

\begin{tabular}{c||c|c|c|c|c}
\hline & 2011 & 2012 & 2013 & 2014 & 2015 \\
\hline Moran' $^{\prime} I$ & 0.2414 & 0.2433 & 0.1857 & 0.1987 & 0.1658 \\
$E(I)$ & -0.0333 & -0.0333 & -0.0333 & -0.0333 & -0.033 \\
Variance & 0.0122 & 0.0123 & 0.0119 & 0.0119 & 0.0120 \\
$Z$ score & 2.4905 & 2.4976 & 2.0097 & 2.1292 & 1.8189 \\
$P$ value & 0.0128 & 0.0125 & 0.0445 & 0.0332 & 0.0689 \\
\hline
\end{tabular}

Table 1. The result of global Moran's analysis

and kernel bandwidth are the most important parameters in GWR model.

The general regression model ignores the local heterogeneity among variables (Bai and Zhang, 2014), while, in GWR model, we embed the spatial position characteristics of the research data, and we use the observations from neighboring data to estimate the local regression. This variable varies with the spatial position so that it reflects the spatial heterogeneity between dependent variables and independent variables (Wang, 2013).

\section{EXPERIMENT AND ANALYSIS}

\subsection{Global Spatial Pattern of E-commerce}

We collected the data of the annual e-commerce turnover of 31 provinces in China from 2011 to 2015 . We used the global moran model to analyze the spatial distribution pattern and the results are shown in Table ??. We can find that Moran 's I is higher than $E(I)$ in 2011-2015, which indicates that e-commerce in China has positive spatial autocorrelation at the provincial level in five years. The provinces with high e-commerce turnover are often adjacent to the provinces which are also with high values.

We make a significance test to the results and find that the results in 2011-2014 meet the standard of 5\% significance test, and the result in 2015 only meets the standard of $10 \%$ significance test. It can be seen that the spatial distribution of the e-commerce development is non-random, but rather showing the geographical agglomeration between similar values.

However, from the overall perspective, Moran's I fluctuates within a certain range and has a downward trend, from 0.241401 in 2011 down to 0.165808 in 2015 . It shows that the geographical agglomeration of e-commerce in China gradually weakens. This may be because when e-commerce just rose in early years, it was only promoted and applied in certain provinces. With the development of technology and changes of people's minds, the provinces have begun to attach the importance to e-commerce. The differences of e-commerce development between regions began to shrink, which gradually breaks the pattern of the past gathering. In addition, the analysis of the $\mathrm{Z}$-value significance test in 2015 also shows that the e-commerce turnover in high value relatively distributes randomly. While the data in the previous few years shows that the e-commerce turnover in high value is more inclined to focus on clustering in some certain provinces.

\subsection{Local Spatial Pattern of E-commerce}

We use local moran model to find the hot spots and cold spots of e-commerce development, and to find the specific distribution pattern of e-commerce in the space (Zhong et al., 2014). We build local moran model of the annual e-commerce turnover in 20112015 and map out LISA clustering thematic maps in five years. 


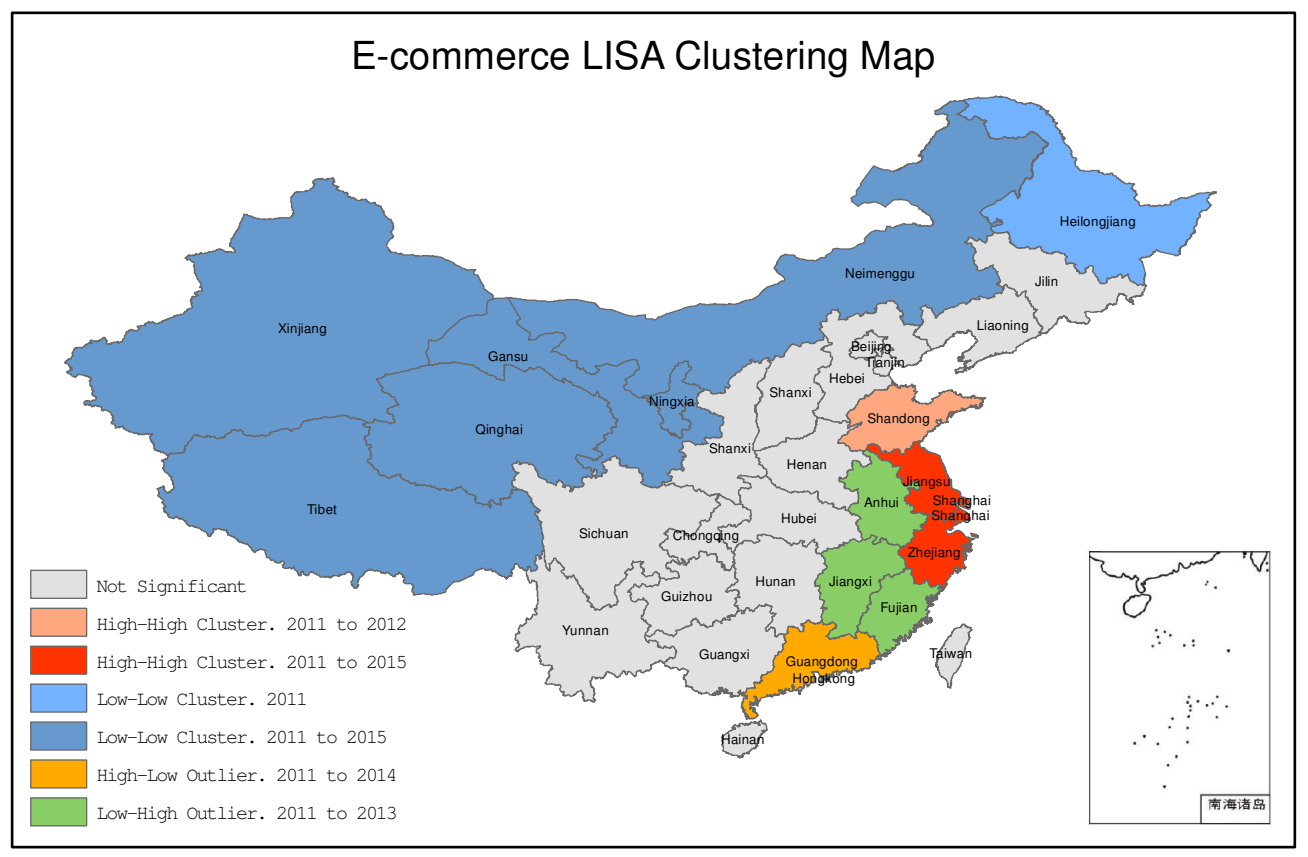

Figure 1. LISA clustering analysis of e-commerce by using local Moran's model

\begin{tabular}{|c|c|c|c|c|c|c|c|c|c|c|c|c|c|c|c|}
\hline \multirow[t]{2}{*}{ Component } & \multicolumn{3}{|c|}{2011} & \multicolumn{3}{|c|}{2012} & \multicolumn{3}{|c|}{2013} & \multicolumn{3}{|c|}{2014} & \multicolumn{3}{|c|}{2015} \\
\hline & $\begin{array}{l}\text { Eigen } \\
\text {-value }\end{array}$ & $\begin{array}{c}\text { Contri } \\
\text {-bution } \\
\text { rate }\end{array}$ & $\begin{array}{l}\text { Cumul } \\
\text {-ative } \\
\text { contri } \\
\text {-bution }\end{array}$ & $\begin{array}{l}\text { Eigen } \\
\text {-value }\end{array}$ & $\begin{array}{c}\text { Contri } \\
\text {-bution } \\
\text { rate }\end{array}$ & $\begin{array}{c}\text { Cumul } \\
\text {-ative } \\
\text { contri } \\
\text {-bution }\end{array}$ & $\begin{array}{l}\text { Eigen } \\
\text {-valuee }\end{array}$ & $\begin{array}{c}\text { Contri } \\
\text {-bution } \\
\text { rate }\end{array}$ & $\begin{array}{c}\text { Cumul } \\
\text {-ative } \\
\text { contri } \\
\text {-bution }\end{array}$ & $\begin{array}{l}\text { Eigen } \\
\text {-value }\end{array}$ & $\begin{array}{c}\text { Contri } \\
\text {-bution } \\
\text { rate }\end{array}$ & $\begin{array}{c}\text { Cumul } \\
\text {-ative } \\
\text { contri } \\
\text {-bution }\end{array}$ & $\begin{array}{l}\text { Eigen } \\
\text {-value }\end{array}$ & $\begin{array}{c}\text { Contri } \\
\text {-bution } \\
\text { rate }\end{array}$ & $\begin{array}{l}\text { Cumul } \\
\text {-ative } \\
\text { contri } \\
\text {-bution }\end{array}$ \\
\hline 1 & 6.028 & 54.804 & 54.804 & 5.906 & 53.691 & 53.691 & 5.742 & 52.202 & 52.202 & 5.620 & 51.094 & 51.094 & 5.568 & 50.620 & 50.620 \\
\hline 2 & 2.897 & 26.334 & 81.138 & 2.892 & 26.295 & 79.986 & 2.928 & 26.622 & 78.823 & 2.613 & 23.757 & 74.851 & 2.784 & 25.309 & 75.929 \\
\hline 3 & 1.128 & 10.254 & 91.392 & 1.094 & 9.947 & 89.933 & 1.182 & 10.749 & 89.572 & 1.407 & 12.789 & 87.640 & 1.066 & 9.693 & 85.622 \\
\hline 4 & 0.399 & 3.626 & 95.018 & 0.482 & 4.379 & 94.312 & 0.431 & 3.920 & 93.492 & 0.589 & 5.351 & 92.991 & 0.604 & 5.491 & 91.113 \\
\hline 5 & 0.226 & 2.051 & 97.069 & 0.294 & 2.670 & 96.982 & 0.316 & 2.869 & 96.361 & 0.333 & 3.026 & 96.017 & 0.492 & 4.476 & 95.589 \\
\hline 11 & 0.003 & 0.031 & 100.000 & 0.005 & 0.044 & 100.000 & 0.005 & 0.043 & 100.000 & 0.005 & 0.042 & 100.000 & 0.005 & 0.043 & 100.000 \\
\hline
\end{tabular}

Table 2. Eigenvalues and variance contribution rates of the principal component analysis

According to Figure 1, the regions with low value of e-commerce turnover are mainly concentrated in the northwest China; the regions with high value of e-commerce turnover are mainly concentrated in the eastern and southeastern coastal areas E-commerce turnover has a decreasing trend from the eastern coastal to the inland. The main pattern of e-commerce development in 5 years did not change too much.

In 2011 and 2012, provinces in high-high cluster pattern were Zhejiang, Jiangsu, Shanghai and Shandong, indicating that these provinces began to develop e-commerce ealier and promoted each other. The next three years, the formation of a stable cluster to Jiangsu, Zhejiang and Shanghai as the core of the business district, leads a rapid development in Yangtze River delta region.

Xinjiang, Qinghai, Gansu are the core of the low-low cluster areas and the development of e-commerce is relatively slow in these regions. These provinces are adjacent to each other and fall in the third quadrant of the Moran Scatter. It is worth mentioning that in 2011, Heilongjiang is also located in the low-low cluster areas, indicating that the development of the Northeast in the past is relatively backward. While, in recent years, its e-commerce strength gradually increases, and there is a significant difference between Northeast and Northwest now.

Analysis for Guangdong, it is in the high-low outlier mode. The level of its e-commerce development is high, but it is surrounded by low-value provinces. Due to the geographical location of Guangdong Province, whose transportation is very convenient, it is suitable for the e-commerce development. In contrast, Fujian, Jiangxi, Anhui and other places, which are adjacent to Guangdong, the economic strength of these provinces is relatively weak. Because they are on the south side of the high-high cluster area in Yangtze River Delta, and on the north side of Guangdong, that forms a low-high outlier pattern. However, from the trend of 5year data, these provinces are developing e-commerce in an increasing pace, and the gap with the surrounding areas is gradually reduced. For example, the result shows that the dispersed pattern is no longer significant in 2014-2015, and the thematic maps have not show these characteristics again.

\subsection{Dimensionality Reduction of Original Data}

We standardize the original data to exclude the impact of different dimensions and orders of magnitude on the evaluation results, 


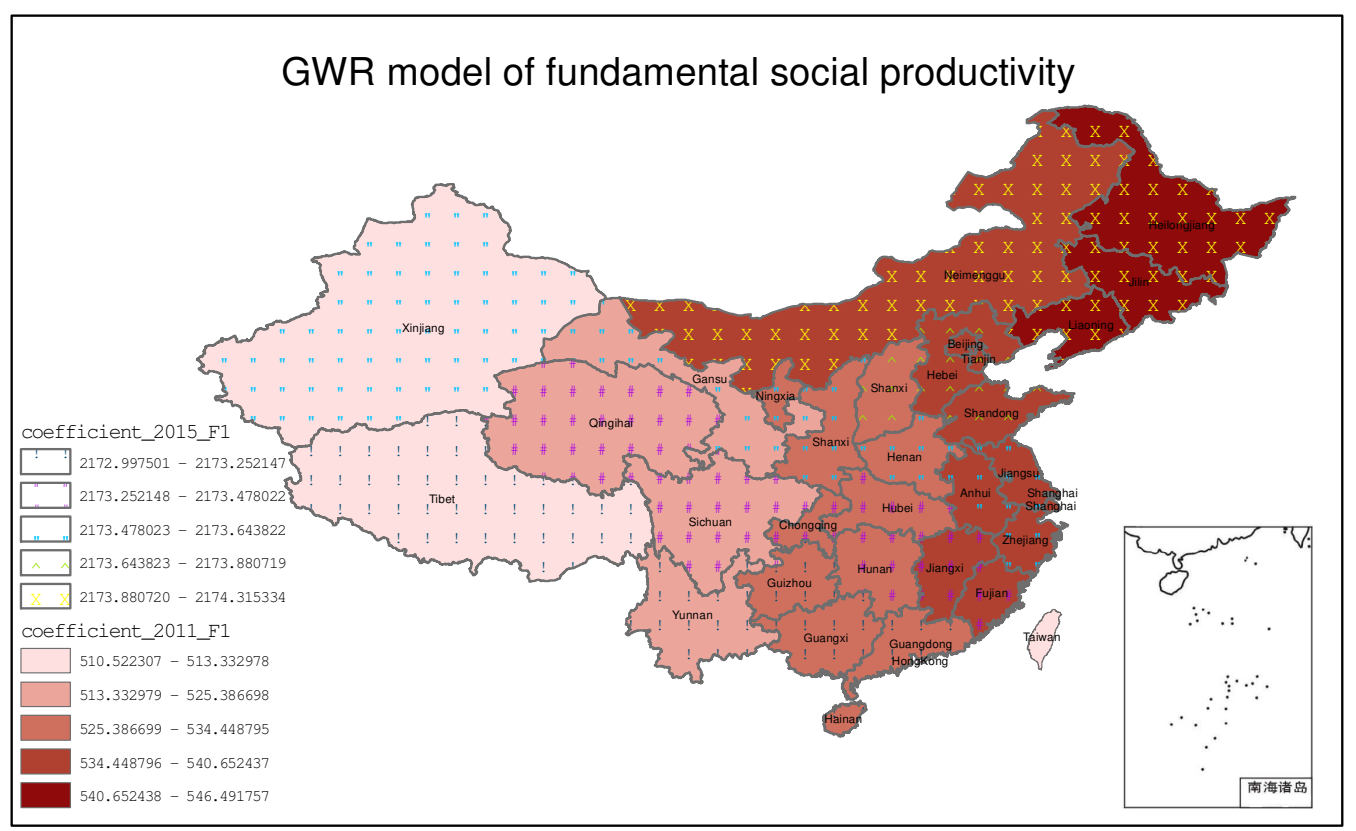

Figure 2. The regional difference map of fundamental social productivity influencing factor in GWR model

and ensure the objectivity and scientificity of the results of principal component analysis (Chen et al., 2014). Then, the normalized data are analyzed by principal component analysis. Generally, $n$ principal components with eigenvalues greater than 1 and cumulative contribution greater than $85 \%$ are selected. The eigenvalues and contribution rates of the analysis are shown in Table ??. The results of the analysis of the data from 2011 to 2015 are similar. The eigenvalues of the first three principal components are more than 1 , and the cumulative contribution rates are $91.392 \%$, $89.933 \%, 89.572 \%, 87.640 \%$ and $85.622 \%$. The first three principal components basically can reflect most of the original information. Therefore, we replace 11 original variables with these three components to reduce the complexity and dimension of the original data.

In order to make the factor easier to be identified and explained, the initial component matrix is rotated through the maximum variance method (Chen et al., 2014). It can be seen from the factor rotation matrix in Table ?? (an example in 2011). The first principal component mainly includes express delivery turnover, the number express delivery goods, the number of express delivery outlets, the number of Internet users, provincial GDP and provincial population. Its contribution rate is $54.804 \%$, and it mainly reflects the fundamental social productivity. The second principal component mainly includes Internet popularity rate, the level of consumption, the proportion of the population aged 1665 , and the proportion of the population with high school education. Its contribution rate is $26.334 \%$, and it mainly reflects the resident living standards. The third principal component mainly reflects the population sex structure, and its contribution rate is $10.254 \%$.

The principal component is a linear combination of 11 normalized indexes. The final score of three principal components F1, F2 and F3 is calculated through multiplying the score coefficien$\mathrm{t}$ matrix and the normalization index. We can make use of the results of principal component analysis to apply the geography weighted regression analysis in the next step.

\begin{tabular}{c|ccc}
\hline & \multicolumn{3}{|c}{ Component } \\
\hline & 1 & 2 & 3 \\
\hline the turnover of express & 0.670 & 0.639 & -0.280 \\
the number of express goods & 0.733 & 0.584 & -0.174 \\
the number of exprss outlets & 0.929 & 0.238 & -0.127 \\
the number of Internet users & 0.971 & 0.135 & -0.013 \\
Internet popularity rate & 0.216 & 0.926 & 0.066 \\
the provincial GDP & 0.956 & 0.195 & 0.121 \\
the level of consumption & 0.250 & 0.926 & -0.057 \\
the provincial population & 0.928 & -0.247 & 0.022 \\
the provincial sex ratio & -0.027 & 0.120 & 0.974 \\
the structure of age in population & -0.016 & 0.864 & 0.301 \\
the structure of education in population & -0.011 & 0.889 & 0.014 \\
\hline
\end{tabular}

Table 3. Rotation component matrix

\subsection{Influencing Factors of E-commerce}

In order to find the influencing factors of e-commerce development and its spatial differences, we use the above three comprehensive factors to build the geographic weighted regression model as follows:

$$
\begin{aligned}
y_{i}= & \beta_{0}\left(u_{i}, v_{i}\right)+\sum_{j=1, k} \beta_{1}\left(u_{i}, v_{i}\right) x_{i j}(\text { SocialProductivity })+ \\
& \sum_{j=1, k} \beta_{2}\left(u_{i}, v_{i}\right) x_{i j}(\text { LivingStandard })+ \\
& \sum_{j=1, k} \beta_{3}\left(u_{i}, v_{i}\right) x_{i j}(\text { SexStructure })
\end{aligned}
$$

We analyze the data from 2011 to 2015 by using the GWR and OLS models. Through comparing the results in Table ??, we find that the $R^{2}$ Adjusted value of GWR is larger. Therefore, the GWR model is more reasonable.

We further analyze the regression coefficients of the variables estimated by the GWR model, and we plot out the regional dif- 


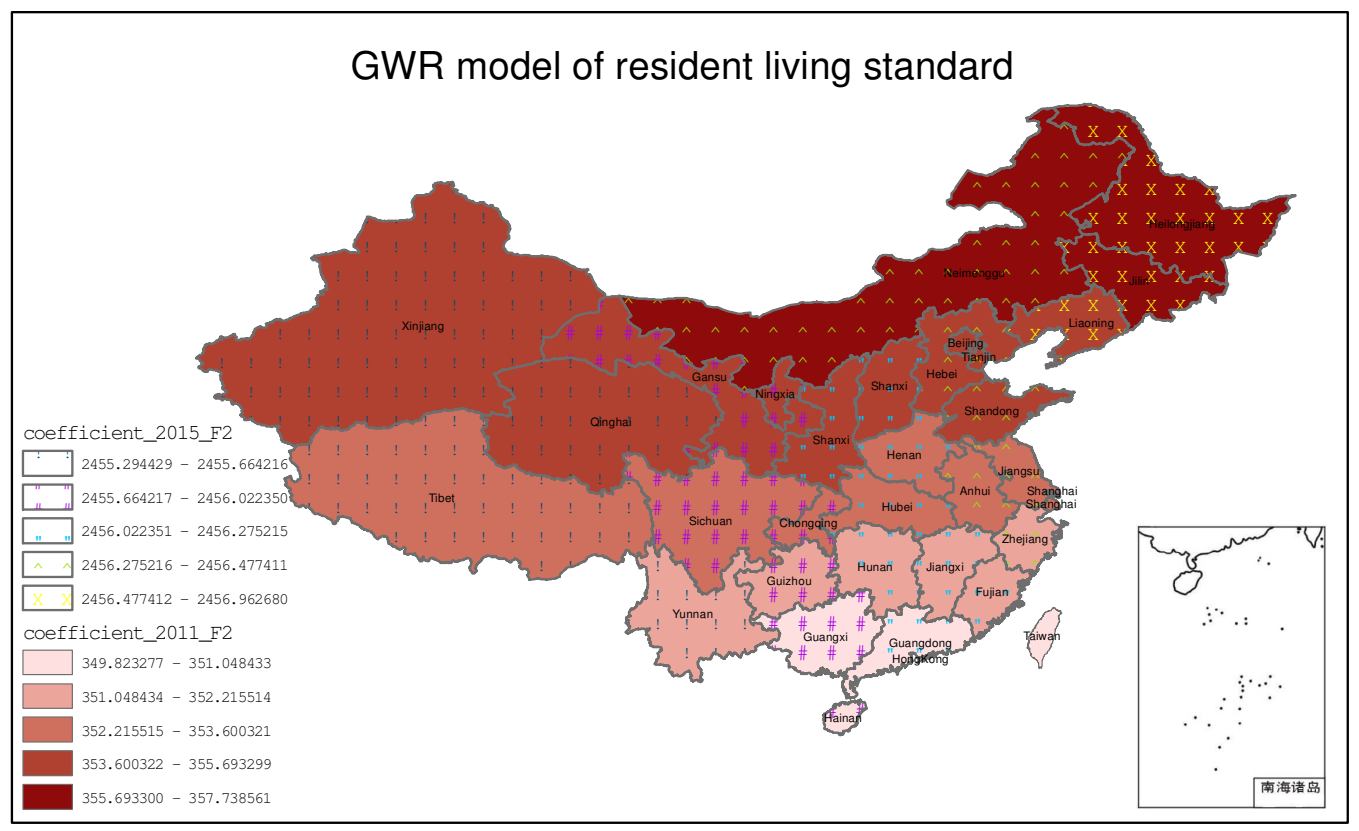

Figure 3. The regional difference map of resident living standard influencing factor in GWR model

ference for the influence of 3 comprehensive factors on the ecommerce development.

(1) According to Figure 2, the regression coefficient of the fundamental social productivity is larger than 0 , indicating that it has a positive correlation with the e-commerce development (Shan and Nie, 2014). From 2011 to 2015, the absolute value of the regression coefficient is increasing year by year. The contribution to e-commerce of this comprehensive factor is growing from 2010. It shows that the development of e-commerce and economy are closely related. The influence of fundamental social productive is different in space, and the regression coefficient of the northeastern provinces is decreasing continuously. The development of e-commerce in Xinjiang, Tibet and Qinghai is relatively slow. These provinces cannot keep up with the pace of its economic development, and the strength of this influencing factor is weak there. From the tendency of change in 2011-2015, it is obvious to see that the strength of this influencing factor is higher in eastern regions and lower in western regions at the beginning. While it gradually transfers the spatial pattern in which the the strength of this influencing factor in the northeast to the southwest is continuously decreasing. Moreover, the difference between the provincial regression coefficients becomes smaller, indicating that the impact of fundamental social productivity on the provinces tends to fluctuate in a smaller range. With the continuous development of the economy, every province has paid attention to e-commerce, and it has a lot of room to improve.

(2) According to Figure 3, the regression coefficient of resident living standard is larger than 0 , indicating that it has a positive effect on the e-commerce development. With the change of time, the spatial pattern of intensity of resident living standard has also changed. The strength of this influencing factor is higher in northern regions and lower in southern regions at the beginning. While it gradually transfers the spatial pattern in which the strength of this influencing factor is higher in eastern regions and lower in western regions year after year.Among them, the continuous improvement of the Internet and education provide a certain foundation for the rapid development of e-commerce. The increase in per capita consumption level stimulates people's desires of on- line shopping. E-commerce in the eastern coastal areas is better, and the resident living standard is also higher there, forming a virtuous circle of mutual promotion.

(3) According to Figure 4, the value of regression coefficient of population sex structure shows rare clustering characteristic in space. According to the analysis results from 2011 to 2015, the values are small and irregularly changes through years. It indicates that the proportion of women has negligible effect on ecommerce and its spatial pattern tends to be randomly distributed. The high-value and low-value regions are different in every year. For example, in 2011, there is a pattern in which the strength of this factor is higher in eastern regions and lower in western regions. While in 2012, the west is higher than that in the east. The results cannot explain the correlation between the population sex structure and the e-commerce development. It is worth noting that the coefficient of Yangtze River delta has always been positive. The possible explaination to account for this phenomenon is that the level of economic development in the Yangtze River Delta is high, so the demand for online shopping is also high, and women are the main crowd of online shopping.

\section{CONCLUSION}

Through the global moran's analysis, there is a certain geographical agglomeration of the e-commerce development in China, and this agglomeration is gradually weakening. Through the local moran's analysis, the low value of e-commerce in China is mainly concentrated in Xinjiang, Qinghai, Gansu as the core of the northwest, and high value gathers mainly in Jiangsu, Zhejiang and other eastern and southeast coastal areas. The provinces in high-low outlier pattern are mainly in Guangdong Province, and their gap with neighboring provinces is decreasing, and the disperse pattern is no longer significant. In general, it is obvious to see that the spatial aggregation of e-commerce development follows certain rules, and it reflects a strong imbalance characteristic.

Through the principal component analysis, three principal components were used: fundamental social productivity, resident liv- 


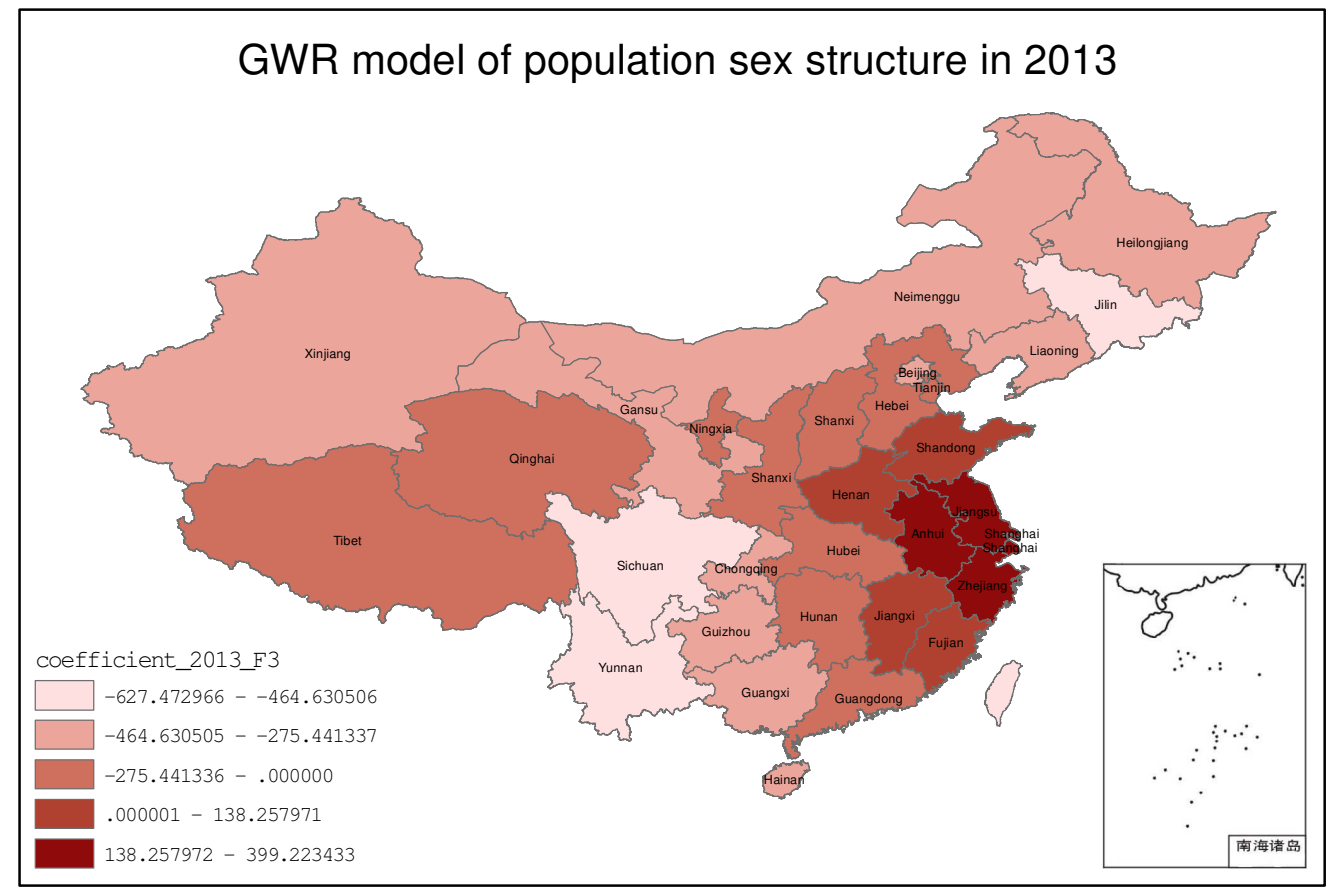

Figure 4. The regional difference map of population sex structure influencing factor in GWR model

\begin{tabular}{c|cc|cc|ccc|cc|cc}
\hline & 2011 & & 2012 & 2013 & & 2014 & & 2015 \\
\hline & AICc & $R^{2}$ Adjusted & AICc & $R^{2}$ Adjusted & AICc & $R^{2}$ Adjusted & AICc & $R^{2}$ Adjusted & AICc & $R^{2}$ Adjusted \\
\hline GWR & 450.5629 & 0.8158 & 474.9662 & 0.9012 & 521.6660 & 0.8663 & 546.5994 & 0.8221 & 548.2064 & 0.8262 \\
OLS & 450.6166 & 0.8142 & 477.3576 & 0.8847 & 523.5297 & 0.8439 & 546.8821 & 0.8175 & 550.9197 & 0.8103 \\
\hline
\end{tabular}

Table 4. The comparison of GWR and OLS model

ing standard and population sex structure. Through the geographical weighted regression analysis, we find that compared with the OLS model, the GWR model has better effect of fitting the influencing factors. There is a positive correlation between the fundamental social productivity and the e-commerce development. The resident living standard is the second most positive influencing factor. And the population sex structure has no significant effect on the e-commerce.

The influence of the first two factors is difference in space, and there is a certain change in the time dimension. The strength of fundamental social productivity is higher in the east and lower in the west at the beginning. It gradually transfers into a pattern that the strength of this factor is continuously decreasing from the northeast to the southwest. The strength of resident living standard is higher in the north and lower in the south at the beginning. It gradually transfers into a pattern that the strength of this factor is higher in the east and lower in the west year after year. And the influence of the two is increasing, which indicates that the above driving factors are becoming more and more important for the development of e-commerce.

On the basis of this analysis, we can choose the suitable model to forecast the development of E-commerce, and further analyze the trend of e-commerce in the time and space dimensions.

\section{REFERENCES}

Aoyama, Y., 2003. Sociospatial dimensions of technology adoption: recent m-commerce and e-commerce developments. Envi- ronment and Planning A 35(7), pp. 1201-1221.

Bai, J. and Zhang, H., 2014. Spatial-temporal analysis of economic growth in central plains economic zone with eof and grw methods. Geographical Research 34(12), pp. 1488-1496.

Chen, H., Cao, C., Zhang, C., Li, W., Qiao, Y., Du, S. and Zhao, Z., 2014. Principal component cluster analysis of effects of longterm fertilization on fertility of lime concretion black soll. Acta Pedologica Sinica 51(3), pp. 609-617.

Farag, S., Weltevreden, J., Van Rietbergen, T., Dijst, M. and van Oort, F., 2006. E-shopping in the netherlands: does geography matter? Environment and Planning B: Planning and Design 33(1), pp. 59-74.

Hao, F., Guan, H. and Wang, S., 2016. Study on the influencing factors and spatial distribution of electronic commerce development level in china's cities. Economic Geography 36(2), pp. 110 .

Shan, Y. H. and Nie, J. C., 2014. Influencing factors of residential land price in wuhan based on gwr model. Journal of Huazhong Agricultural University 113(5), pp. 111-118.

Tang, Y., 2015. A spatial difference study on china's e-commerce development level. Economic Geography 35(5), pp. 9-14.

Wang, K., 2013. Spatial estimation of soil organic matter by using geographically weighted regression model. Chinese Journal of Soil Science 44(1), pp. 21-28. 
Wang, X. and Xu, S., 2011. Spatial autocorrelation analysis of c2c e-business in china. Economic Geography.

Wang, Y., Wang, J., Yao, Y. and Wang, J., 2014. Evaluation of drought vulnerability in southern china based on principal component analysis. Ecology \& Environmental Sciences 23(12), pp. 1897-1904.

Xiao, W. D., 2014. Spatial statistics analysis of china's planting geographic agglomeration. Economic Geography 34(9), pp. 124129.

Xu, S., 2013. Research on Geographic Pattern of Chinas C2C E-commerce. PhD thesis, Dalian University of Technology.

Zhong, H., Zhang, Shaozhong, H. L. and Nie, Y., 2014. Spatial pattern of c2c e-commerce online shops in china. Economic Geography 34(4), pp. 91-96.

Zhu, B., Song, Y., Li, G. and Yu, T., 2016. Spatial aggregation pattern and influencing factors oftaobao villagein china under the c2c e-commerce mode. Economic Geography 36(4), pp. 92-98. 